\title{
Why Haven't Regional Wages \\ Converged?
}

J a son L Sa ving

Federal Reserve Bank of Dallas

Research Department

Working Paper 1711

https://doi.org/10.24149/wp1711 


\title{
Why Haven't Regional Wages Converged?
}

\author{
By \\ Jason L. Saving \\ Senior Research Economist and Advisor, Federal Reserve Bank of Dallas*
}

December 18, 2017

Regional wage convergence has long been predicted across the United States as barriers to factor mobility have fallen, yet there is little evidence (apart from a brief period in the 1970s and 1980s) that convergence has actually occurred. Why not? I reexamine this issue by developing a model in which fiscal policy differences across states endogenously impact labor supply across jurisdictions. I find that states whose safety nets are relatively generous will tend to drive out workers, raising wages for those who remain while also prompting net outmigration to less generous states. This suggests that regional wage convergence requires not only free factor mobility but also the coordination of fiscal policy across jurisdictions. (JEL H73.

Keywords: regional wage convergence, fiscal federalism.)

\footnotetext{
* The views expressed here are those of the author and do not necessarily reflect those of the Federal Reserve Bank of Dallas or the Federal Reserve System. I thank Alex Richter, Michael Plante, John Duca, Leonard Nakamura, Michael Weiss, and seminar participants at the Federal Reserve Bank of Dallas. I also thank conference participants at the Southern Economic Association conference in Tampa, Florida for constructive comments. Any remaining errors are my own.
} 


\section{Introduction}

As economic integration proceeds in a federation, one outcome predicted by social science research is the convergence of wages across jurisdictions. This convergence occurs for several reasons including the movement of capital, the migration of people, and often the greater prevalence of laws and regulations from the center vis-à-vis member states. To be sure, persistent differences in culture, language, and other factors may slow this convergence even within countries (say, comparing southern and northern Italy) but the expectation is that convergence will happen over a sufficiently lengthy long run ${ }^{1}$.

One might expect the United States to be among the federations whose member state wages have made the most progress toward convergence. After all, the country has since at least the Civil War developed a common national identity, with a common currency and a generally spoken language, and has for the last half-century at least offered convenient interstate highways for exceptionally rapid movement across jurisdictions. And at least until the mid-1980s, there was some reason to believe these phenomena had coupled with globalization and technological change to produce a powerful trend toward regional wage convergence, both within the U.S. and between the U.S. and Mexico [Hanson 1996 and 1997, Robertson 2000].

Yet this trend was not sustained, either in the United States [Phillips 1992] or across the international border [Gandolfi et al 2014]. Explanations provided for the lack of convergence

1 See Magrini (2004) for an excellent summary of the economics of regional convergence as well as some of the difficulties in evaluating whether such convergence has occurred. 
include differing propensities to migrate across education and income levels [Mishra 2007], differentials in regional exposure to world trade [Autor et al 2013], and residual barriers to capital and good movements that may be larger than previously thought [Robertson 2005]. While varying somewhat in their particulars, however, each of these explanations assumes regional wages would converge if only barriers to mobility could be removed and/or industrial compositions costlessly reshuffled.

In this paper, I present an alternative explanation for the lack of wage convergence that focuses on differences in regional fiscal policy. I take as my starting point the assumption that the factors of production are costlessly mobile across jurisdiction, abstracting away in particular from the barriers to labor mobility that are said to impede convergence. I then ask whether one would expect regional wage convergence to occur. If it can be shown that convergence would occur in the absence of barriers, then policymakers who wish to pursue convergence might reasonably engage in measures to mitigate those barriers, whether they be more generous permit systems for cross-border migration, larger fiscal transfers that would raise (lower) after-tax wages in poorer (richer) jurisdictions, or fewer labor-market structures like employer-provided health care that "lock in" workers to particular jobs in particular jurisdictions. On the other hand, if convergence would not occur even in a world without barriers or frictions, then current efforts (extensive in some countries/regions) to bring about convergence by fostering factor mobility may perhaps need to be rethought.

Beyond the relevance to these particular programs, the question of regional wage convergence bears on the efficient division of responsibilities across levels of government. The fiscal federalism literature begun by Oates [1973] outlines a wide swathe of government services that are best provided at the state or local level, though there are significant empirical issues with 
how to properly categorize them and warnings that improper categorization could swamp any potentials gains from decentralization [Prud'homme 1995]. Balanced against this with others extending the analysis or even suggesting a robust federal system can help reduce overall government spending in a federation [Rodden 2003] or even preserve a market economy within the federation as a whole [Weingast 1995, Qian and Weingast 1997]. While this paper does not directly address these issues, a finding that regional wage convergence is affected by fiscal decentralization would suggest some level of caution regarding that decentralization may be warranted.

The main respect in which fiscal policy will differ in my model is the safety-net level jurisdictions select. When individuals are free to migrate across states in response to differentials in wages and welfare benefits, states that offer generous welfare benefits will attract recipients and repel workers. ${ }^{2}$ This phenomenon will in turn raise prevailing wages in highbenefit jurisdictions while reducing them in low-benefit jurisdictions, ensuring regional wage convergence won't - and can't - occur in a world where jurisdictions can pursue their own independent fiscal policies.

\section{How Are Benefit Levels Related to Wages?}

Putting this model in context requires first discussing how traditional work viewed the interplay between benefits and wages. Traditional labor and public finance models began with

\footnotetext{
${ }^{2}$ There is an extensive empirical literature on the extent to which welfare benefit levels induce recipient migration, a thesis most famously formulated in Peterson and Rom [1989,1990]. Bailey [2005] provides an excellent summary of the evidence to date, concluding such migration exists but is not a dominant factor in mobility decisions.
} 
the proposition that individuals are altruistic with decreasing marginal utility of income [e.g. Gramlich and Laren 1984]. According to this explanation, areas with higher prevailing wages would tend to offer more generous safety nets, not because they are more compassionate but simply because they have a greater availability of funds. Similarly, states with lower prevailing wages would tend to offer sparser social protections even if equally altruistic. Alternatively, economists such as Varian [1990] viewed state safety net levels as stemming mainly from the desire for social insurance. According to this line of reasoning, high-wage workers are more willing to part with any given amount of income, and can therefore be expected to give more to the poor, mainly as a hedge against the possibility of involuntary unemployment.

Either way, the relationship between benefits and wages would be straightforward, with higher-wage jurisdictions offering more generous safety nets because higher-wage individuals are more inclined to provide them [Moffitt et al 1998]. This insight led in turn to the natural expectation that, as wages converged, electorates would naturally wish to raise their state safety nets as well, with welfare benefit levels ultimately equalizing across jurisdictions in line with wage convergence. Insights garnered from the charitable contribution literature were key to this expectation, showing for example that high-wage workers make larger charitable contributions to the poor [Feldstein and Clotfelter 1976, Steurle 1987]. With ever-greater economic integration in the US fostering factor mobility, it would only be a matter of time before then-poor jurisdictions improved their safety nets as residents of those states saw improvements in their wages.

For this analysis to hold, it must be the case that preferences over benefit levels are an increasing function of wages. But do higher-wage individuals actually favor more generous safety nets than their lower-wage counterparts? While it is true that they make larger charitable 
contributions, there are important ways in which charitable contributions differ from government-run welfare programs. First, those who contribute to charity can choose the set of people to whom they give and the amount given, while those who "contribute" to the government can do neither. More importantly, individuals bear the full cost of their charitable contributions but only a small portion of the cost of government welfare programs, which suggests that benefit-level preferences may be determined as much by one's willingness to redistribute the income of others as by the marginal utility of one's own income. Finally, the presence of progressive taxation substantially increases the marginal cost of welfare benefit provision for high-wage workers while reducing or even eliminating it for low-wage workers.

Taken together, then, it is not clear a priori that one should expect to see high-wage individuals favoring relatively generous social insurance programs. Indeed, survey evidence from the United States is inconsistent with this expectation. For example, a survey by the Pew Research Center found that $59 \%$ of individuals in the lowest income quartile favored greater expenditures on welfare recipients versus whereas only $29 \%$ of individuals in the highest income quartile who expressed similar views. An NPR/Kaiser/Kennedy School survey reached qualitatively similar findings, though with a smaller gap. ${ }^{3}$ While the available evidence does not definitely find a negative relationship between income and one's preferred benefit level, it is certainly not consistent with a positive relationship.

To be sure, these and other surveys ask imperfectly worded questions and do not carefully distinguish between various classes of welfare programs, so no single survey should be taken as definitive evidence on this point. But the overall weight of the evidence cuts against the

\footnotetext{
${ }^{3}$ This survey was taken in 2001 and provides no data on the views of upper-income Americans.
} 
argument that high-wage individuals naturally support higher benefit levels, which I take as a starting point for the work that follows.

If wages do not drive benefit levels, though, how can the observed relationship between benefits and wages be explained? In the model given here, generous safety nets endogenously cause high wages through the channel of migration. More specifically, when individuals are free to migrate across states in response to differentials in wages and welfare benefits, states that offer generous welfare benefits will attract recipients and repel workers. ${ }^{4}$ This migration of workers raises the prevailing wage in high-benefit states and lowers the prevailing wage in low-benefit states, consistent with the empirically observed positive relationship between safety nets and wages in the United States. And the nature and direction of the causal relationship turns out to have important implications for regional, and national, fiscal policy decisions.

\section{Model and Results}

Interjurisdictional models which permit migration often assume that individuals differ in some exogenous earnings parameter and migrate in response to differentials in the price of housing [e.g. Epple and Romer 1991]. More recent work utilizes a neo-Ricardian framework in which each individual receives both an endogenously determined wage and some welfare benefit level offered by his jurisdiction of residence and migrates in order to maximize their sum [e.g. Wildasin 1991]. Each of these models presents problems in an attempt to explain the wage-

\footnotetext{
${ }^{4}$ There is an extensive empirical literature on the extent to which welfare benefit levels induce recipient migration, a thesis most famously formulated in Peterson and Rom [1989,1990]. Bailey [2005] provides an excellent summary of the evidence to date, concluding such migration exists but is not a dominant factor in mobility decisions. The impact on workers is largely unexplored at this point.
} 
benefit correlation in the United States, where labor markets are relatively flexible and relatively few individuals receive both benefits and wages. In this section, I develop a model that combines the wage flexibility of American labor markets with wage-welfare exclusivity.

When wages and welfare benefit levels differ across jurisdictions, individuals have an incentive to "vote with their feet" and migrate toward jurisdictions that offer higher wages or more generous welfare benefits. Abstracting away from any costs associated with migration, individuals will move until interjurisdictional differences in well-being disappear. ${ }^{5}$ In order for this to occur, there must be some mechanism through which the net incomes of workers and recipients is congestible. ${ }^{6}$ In the case of workers, decreasing marginal productivity of labor provides a natural avenue for this congestion to operate: wages fall as the number of workers rise. In the case of recipients, the answer is less clear because welfare benefit levels are set by statute and do not respond (at least not directly) to changes in the recipient population. ${ }^{7}$ For this reason, labor markets cannot be the sole means by which individual well-being is equilibrated across jurisdictions.

I shall assume in this paper that both recipients and workers value locational amenities as well as welfare benefits and wages. It is well known that amenities affect the migration decisions of individuals [Rosen 1979, Graves and Linneman 1979]. In fact, empirical work suggests that

${ }^{5}$ In general, the qualitative conclusions of this paper hold when mobility is costly, although interjurisdictional differentials smaller than the cost of mobility would persist in equilibrium.

${ }^{6}$ If this were not the case, the system would equilibrate at a "corner solution" in which each type of mobile individual would reside in exactly one jurisdiction. Such a system would offer scant theoretical or empirical insight.

${ }^{7}$ It might still be possible that politicians respond to such migration by altering welfare benefit levels, but the empirical evidence for this is at best mixed [Moffitt 1992]. 
regional wage differentials are largely a function of amenity differentials [Roback 1982]. While some amenities are independent of population size, most are in some way subject to congestion effects. Examples include beaches, public parks, and even the crime rate, which increases with increasing population density. As long as locational amenities are at least at the margin congestible, they can provide the means by which recipient net income equilibrates across jurisdictions.

Assume two types of individuals in the model, workers and recipients, who are costlessly mobile across a fixed number of jurisdictions. ${ }^{8}$ Let each jurisdiction be endowed with a Ricardian production function $f_{i}\left(e_{i}\right)$ for the numeraire commodity, where $I$ is the jurisdiction of interest and $e_{i}$ is the number of individuals who are employed in the jurisdiction. ${ }^{9}$ This production function is monotonically increasing and concave in the number of workers. Each jurisdiction is also endowed with an amenities function $a_{i}\left(u_{i}+e_{i}\right)$, where $u_{i}$ is the number of individuals who reside in the jurisdiction but are unemployed. The amenities function is assumed to be, at least at the margin, decreasing in its argument.

Workers are endowed with one unit of labor which must be used to produce the numeraire commodity. Each worker receives from his employer the marginal value of labor in production of the numeraire, and no resident who is able to work may be excluded from employment. Recipients, on the other hand, receive subsidies from their local jurisdiction instead

${ }^{8}$ Although I assume that all recipients and workers are mobile, such an assumption is not crucial for the analysis. It should be noted that, when some individuals are immobile, the implication of changes in welfare policy may differ considerably for mobile and immobile individuals.

${ }^{9}$ The production function need not differ across jurisdictions. However, the model is completely general with regard to employer human capital and jurisdictional technology, both of which could generate interjurisdictional differences in the production function. 
of wages from an employer. These subsidies are identical across all recipients in a given jurisdiction, and no unemployed resident may be excluded from the subsidy. For the sake of simplicity, suppose that subsidies are provided by taxation of fixed capital, the owners of which claim all residual profits and finance all redistribution. Further, suppose that each type of mobile individual (recipients and workers) attempt to maximize their net income.

Let the benefits paid to recipients from a given jurisdiction be denoted $b_{i}$ and assume competition so that the wage in a given jurisdiction is $w_{i}=f_{i}^{\prime}\left(e_{i}\right)$. Then the net income of workers and recipients respectively in jurisdiction $I$ is given by

$$
\begin{aligned}
& Y_{i}^{E}=w_{i}+a_{i}\left(u_{i}+e_{i}\right) \\
& Y_{i}^{U}=b_{i}+a_{i}\left(u_{i}+e_{i}\right)
\end{aligned}
$$

Since both workers and recipients are costlessly mobile across jurisdictions, equilibrium net income for both must be identical across all jurisdictions so that,

$$
\begin{aligned}
& w_{i}+a_{i}\left(u_{i}+e_{i}\right)=w_{j}+a_{j}\left(u_{j}+e_{j}\right) \\
& b_{i}+a_{i}\left(u_{i}+e_{i}\right)=b_{j}+a_{j}\left(u_{j}+e_{j}\right)
\end{aligned} \forall i, j
$$

Denote the equilibrium level of net income for workers and recipients respectively as $Y^{E}$ and $Y^{U}$.

Finally, let $M$ be the total number of mobile individuals in the system. Since these individuals are divided into two mutually exclusive types, it must be the case that

$$
\sum u_{i}+\sum e_{i}=M
$$

and

$$
\begin{aligned}
& \sum u_{i}=U \\
& \sum e_{i}=E
\end{aligned}
$$


Now, denote the equilibrium net income differential between workers and recipients by $\Delta$. Since the equilibrium values of $Y^{E}$ and $Y^{U}$ are constant across jurisdictions, the equilibrium value of $\Delta$ is also constant across jurisdictions and is given by

$$
\Delta=Y^{E}-Y^{U}=w_{i}-b_{i}=w_{j}-b_{j} \quad \forall i, j
$$

A rearrangement of this equation yields the relationship $w_{k}=\Delta+b_{k} \forall k$ between welfare benefit levels and wages.

To explore whether wages and benefits are related, suppose that jurisdiction I chooses to increase its subsidy to welfare recipients. An increase in redistribution by jurisdiction $I$ increases the net income of recipients in jurisdiction $I$. It also creates an income differential between recipients in jurisdiction $I$ and recipients in all other jurisdictions, which in turn provides opportunities for migrational arbitrage. Solving implicitly for employment in a given jurisdiction yields $e_{i}=w_{i}^{-1}\left(Y^{E}-Y^{U}+b_{i}\right)$ which implies $e_{i}^{\prime}<0, \forall i$.

Implicitly differentiating (4) with respect to $\boldsymbol{b}_{\boldsymbol{i}}$, we have

$$
\frac{\partial E}{\partial b_{i}}=\frac{\partial \sum e_{k}}{\partial b_{i}} .
$$

Since $\boldsymbol{E}$ is fixed,

$$
\begin{aligned}
& 0=\frac{\partial \sum e_{k}}{\partial b_{i}} \\
& 0=\frac{\partial\left(e_{i}+\sum_{k \neq i} e_{k}\right)}{\partial b_{i}} \\
& 0=e_{i}^{\prime}\left[\frac{\partial\left(Y^{E}-Y^{U}+b_{i}\right)}{\partial b_{i}}\right]+\sum_{k \neq i}\left\{e_{k}^{\prime}\left[\frac{\partial\left(Y^{E}-Y^{U}+b_{k}\right)}{\partial b_{i}}\right]\right\} \\
& 0=e_{i}^{\prime}+\frac{\partial\left(Y^{E}-Y^{U}\right)}{\partial b_{i}} \sum e^{\prime}
\end{aligned}
$$


Rearranging terms, we obtain

$$
\frac{\partial\left(Y^{E}-Y^{U}\right)}{\partial b_{i}}=-\frac{e_{i}^{\prime}}{\sum e_{k}^{\prime}}<0 .
$$

This derivative, which I shall denote by the symbol $\beta_{i}$, measures the marginal impact of a change in redistribution on the distribution of income and is always negative. Since $\beta_{i}^{\prime}<0, \forall i$, the migration of workers induced by a change in $b_{i}$ is given by

$$
\begin{aligned}
& \frac{\partial e_{i}}{\partial b_{i}}=\left(1+\beta_{i}\right) e_{i}^{\prime}<0 \\
& \frac{\partial e_{i}}{\partial b_{j}}=\beta_{j} e^{\prime}>0
\end{aligned}
$$

These equations demonstrate the spillover effect for workers: additional redistribution on the part of jurisdiction $i$ reduces the number of workers in jurisdiction $i$ but raises the number of workers in all other jurisdictions.

Recipient effects may be obtained in a similar manner. Since $Y^{U}=b_{i}+a_{i}\left(u_{i}+e_{i}\right)$, it must be the case that $u_{i}+e_{i}=a_{i}^{-1}\left(Y^{U}-b_{i}\right)$. Substituting this equation into (3) and implicitly differentiating with respect to $b_{i}$ yields

$$
\frac{\partial(U+E)}{\partial b_{i}}=\frac{\partial \sum a_{k}^{-1}}{\partial b_{i}}
$$

Since $U$ and $E$ are fixed, 


$$
\begin{aligned}
0 & =\frac{\partial \sum a_{k}^{-1}}{\partial b_{i}} \\
& =\frac{\partial\left(a_{i}^{-1}+\sum_{k \neq i} a_{k}^{-1}\right)}{\partial b_{i}} \\
& =\left(a_{i}^{-1}\right)^{\prime}\left(\frac{\partial Y^{U}}{\partial b_{i}}-1\right)+\left(\frac{\partial Y^{U}}{\partial b_{i}}\right) \sum_{k \neq i} a_{k}^{-1} \\
& =\left(\frac{\partial Y^{U}}{\partial b_{i}}\right) \sum_{k \neq i}\left(a_{k}^{-1}\right)^{\prime}-\left(a_{i}^{-1}\right)^{\prime}
\end{aligned}
$$

Therefore, it must be the case that the change in net income for recipients is given by

$$
\frac{\partial Y^{U}}{\partial b_{i}}=\frac{\left(a_{i}^{-1}\right)^{\prime}}{\sum\left(a_{k}^{-1}\right)^{\prime}}>0 .
$$

This derivative, which I shall denote by the symbol $\pi_{\mathrm{i}}$, measures the marginal impact of a change in redistribution on the net income of recipients and is always positive.

Since $\pi_{i}>0, \forall i$, the migration of recipients induced by a change in $b_{i}$ is given by

$$
\begin{aligned}
& \frac{\partial u_{i}}{\partial b_{i}}=-\left(1-\pi_{i}\right)\left(a_{i}^{-1}\right)^{\prime}-\left(1+\beta_{i}\right) e_{i}^{\prime}>0 \\
& \frac{\partial u_{j}}{\partial b_{i}}=\pi_{j}\left(a_{i}^{-1}\right)^{\prime}-\beta_{j} e^{\prime}<0
\end{aligned}
$$

These equations demonstrate the spillover effect for recipients: additional redistribution on the part of jurisdiction $i$ raises the number of recipients in jurisdiction $i$ but lowers the number of recipients in all other jurisdictions.

These results suffice to describe the comparative statics associated with wages and benefits. In particular, when a jurisdiction chooses to offer a more generous level of welfare benefits, workers have an incentive to migrate toward other jurisdictions. This migration of workers increases the scarcity of labor in the jurisdiction of interest and decreases the scarcity of 
labor in all other jurisdictions, which in turn raises the prevailing wage in the jurisdiction of interest and lowers the prevailing wage in all other jurisdictions. In equilibrium, the difference between benefits and wages will be exactly the same in every jurisdiction, with increased wages in a particular jurisdiction always accompanied by increased welfare benefits in that jurisdiction.

The implications for wage convergence are both stark and immediate. When states in a federation are allowed to maintain different levels of social protection, wages would not be expected to converge either in the short or the long run. Moreover, in contrast to suggestions that greater factor mobility is needed to facilitate wage convergence, such a development would actually inhibit wage convergence in this framework because workers would then be better able to escape, and recipients better able to seek, high benefit jurisdictions. Only when states offer the same level of social protection would wages be expected to converge across member states.

\section{Implications and Conclusion}

At its core, this paper reinterprets the relationship between safety nets and wages with the member states of a federation. Previous work suggests that high-wage individuals wish to give more to the poor and that this desire naturally leads high-benefit states to offer generous public support for their poor. But this work implicitly assumes that individuals view publicly provided welfare benefits as a natural extension of their private charitable contributions - and government revenue as a natural extension of their own pocketbooks. Because social insurance programs differ from private charity in important ways, it need not be the case that individuals who make large charitable contributions will necessarily also wish to see a relatively generous publicly 
provided welfare system, which is inconsistent with a flow of causation from jurisdictional wages to benefit levels.

This paper provides an alternative explanation in which wages are endogenously determined, with generous safety nets repelling workers and thereby raising wages in those jurisdictions as labor scarcity raises workers' marginal products. Similarly, low welfare benefit levels induce worker inmigration which reduces wages in those jurisdictions. In equilibrium, then, jurisdictions that offer high (low) benefit levels can expect higher (lower) wages to prevail in their jurisdictions.

Once that is understood, the implications for regional wage convergence become clear. In general, one would not expect regional wage convergence to prevail in a federation whether or not there are significant barriers to factor mobility. For this reason, policies to facilitate factor mobility - whether they take the form of improved transportation networks, broader access to financial markets, or greater transferability of benefits from one job to the next - would not be expected to bring about wage convergence even though those policies might well have positive implications for economic growth. And if regional wage convergence did prevail across a federation, then any change to safety-net policy by a member state would disrupt the convergence unless and until that change to fiscal policy were rescinded. Simply put, regional wage convergence cannot occur when individuals are free to migrate and jurisdictions are free to offer different safety-net levels to their residents.

These results contain both good and bad news for proponents of regional wage convergence. If it is desired that regions have the fiscal autonomy to offer the safety-net levels of their choosing, this is feasible, but it must be accepted that wages will differ across those jurisdictions and do so in a predictable manner, with wages in New York City and San Francisco 
(for example) exceeding those of Houston and Atlanta while migration patterns favor the latter two cities over the former. On the other hand, if it is desired that regional wage convergence happen, this too is feasible, but only through a ceding of fiscal autonomy that prevents jurisdictions from offering more (or less) generous safety nets than their counterparts elsewhere.

The central findings of this paper therefore tie into both the well-established literature on fiscal federalism and current debates over the extent to which cities or states should be allowed to pursue autonomous fiscal policies ${ }^{10}$. Past work has generally found safety nets to best function as a joint state-federal endeavor, which balances inter-region equity with the desire for smaller areas to indulge their preferences for progressive/regressive fiscal policies. If regional choices affect overall wage convergence, however, then those choices can mitigate or exacerbate inequality across regions and potentially thwart federal desires to a greater extent than is commonly realized.

The ability of jurisdictions to affect their own prevailing wages also matters in federations that condition inter-regional transfer payments on wages. Programs such as Medicaid in the United States, provincial equalization payments in Canada, and certain development aid in the European Union are designed in such a way that larger payments are made (or more generous matching rates offered) to lower-wage jurisdictions. To the extent wages are endogenous to a jurisdiction's fiscal policies, however, it is unclear that regional transfer payments would properly accomplish the desired objective of helping a regional converge. One implication of this paper, then, is perhaps to prompt a reassessment of the level of government at which safety-net policy should be optimally set.

Finally, the results of this paper bear on issues such as the desire to fight "social

10 See Shah (2006) for an excellent overview of these issues. 
dumping" by states that offer low safety nets and supposedly scoop up workers across the rest of the federation in so doing. Solutions in the European Union and elsewhere have generally taken the form of "social chapters" designed to limit member states' fiscal flexibility in the belief that more similar fiscal policies across the federation would reduce worker outflows (similar to "unfair tax competition" agreements that seek to reduce capital outflows). While addressing the desirability of such agreements is beyond the scope of this paper, this paper suggests they do correctly frame the fundamental tradeoff as one that pits fiscal autonomy against the desire to staunch the flow of labor and capital from one jurisdiction to another. 


\section{Bibliography}

Autor, David H., David Dorn, and Gordon H. Hanson. 2013. "The China Syndrome: Local Labor Market Effects of Import Competition in the United States." American Economic Review 103: 2121-68.

Bailey, Michael A. 2005. "Welfare and the Multifaceted Decision to Move." American Political Science Review 99: 125-135.

Epple, Dennis, and Thomas Romer. 1991. "Mobility and Redistribution." Journal of Political Economy 99: 828-858.

Feldstein, Martin, and Charles T. Clotfelter. 1976. "Tax Incentives and Charitable Contributions in the United States: A Microeconometric Analysis." Journal of Public Economics 5: 27-56.

Gandolfi, David, Timothy Halliday, and Raymond Robertson. 2014. "Globalization and Wage Convergence: Mexico and the United States." IZA Discussion Paper 8254, available through SSRN at https://ssrn.com/abstract=2460157.

Gramlich, Edward M., and Deborah S. Laren. 1984. "Migration and Income Redistribution Responsibilities." Journal of Human Resources 19: 489-511.

Hanson, Gordon H. 1996. "Localization Economies, Vertical Organization, and Trade." American Economic Review 86: 1266-1278.

Hanson, Gordon H. 1997. "Increasing Returns, Trade, and the Regional Structure of Wages." Economic Journal 107: 113-133.

Luttmer, Erzo. 1999. "Group Loyalty and the Taste for Redistribution." Joint Center for Poverty Research Working Paper 61.

Magrini, Stefano. 2004. "Regional (Di)convergence." In Handbook of Regional and Urban Economics, edited by J. Vernon Henderson and Jacques-Francois Thisse, pp. 2741-2796. Amsterdam: Elsevier.

Mishra, Prachi. 2007. "Emigration and wages in source countries: Evidence from Mexico." Journal of Development Economics 82: 180-199.

Moffitt, Robert, David Ribar, and Mark Wilhelm. 1998. "The Decline of Welfare Benefits in the U.S.: The Role of Wage Inequality." Journal of Public Economics 68: 421-452.

Orr, Larry L. 1976. "Income Transfers as a Public Good: An Application to AFDC." American Economic Review 66: 359-371.

Peterson, Paul E., and Mark C. Rom. 1989. "American Federalism, Welfare Policy, and 
Residential Choices." American Political Science Review 83: 711-728.

Peterson, Paul E., and Mark C. Rom. 1990. Welfare Magnets: A New Case for a National Standard. Washington DC: The Brookings Institution.

Phillips, Keith R. 1992. "Regional Wage Divergence and National Wage Inequality." Economic Review - Federal Reserve Bank of Dallas, Fourth Quarter: 31-40.

Prud'homme, Remy. 1995. “The Dangers of Decentralization.” World Bank Research Observer 10: 201-220.

Qian, Yingyi and Barry R. Weingast. 1997. "Federalism as a Commitment to Preserving Market Incentives." Journal of Economic Perspectives 11: 83-92.

Roback, Jennifer. 1982. "Wages, Rents, and the Quality of Life." Journal of Political Economy 90: 1257-1278.

Robertson, Raymond. 2000. "Wage Shocks and North American Labor-Market Integration." American Economic Review 90: 742-764.

Robertson, Raymond. 2005. "Has NAFTA Increased Labor Market Integration between the United States and Mexico?" The World Bank Economic Review 19: 425-448.

Rodden, Jonathan. 2003. "Reviving Leviathan: Fiscal Federalism and the Growth of Government.” International Organization 57: 695-729.

Rosen, Sherwin. 1979. "Wage-Based Indexes of Urban Quality of Life." In Current Issues in Urban Economics, edited by Peter Mieszkowski and Mahlon Straszheim. Baltimore, MD: Johns Hopkins Press.

Shah, A. 2006. "A Practitioner's Guide to Intergovernmental Fiscal Tansfers.” In Intergovernmental Fiscal Transfers: Principles and Practice, edited by Robin Boadway and A. Shah, pp 1-53. Washington, DC: The World Bank.

Steuerle, C. Eugene. 1987. "Charitable Giving Patterns of the Wealthy." In T. Odendahl, ed., America's Wealthy and the Future of Foundations. New York: The Foundation Center.

Tiebout, Charles M. 1956. "A Pure Theory of Local Expenditures." Journal of Political Economy 64: 416-424.

Varian, Hal. 1980. "Redistributive Taxation as Social Insurance." Journal of Public Economics 14: 49-68.

Weingast, Barry R. 1995. "The Economic Role of Political Institutions: Market-Preserving Federalism and Economic Development." Journal of Law, Economics, and Organization 11: $1-31$. 
Wildasin, David E. 1991. "Income Redistribution in a Common Labor Market." American Economic Review 81: 757-774.

Wildasin, David E. 1992. "Relaxation of Barriers to Factor Mobility and Income Redistribution." Public Finance/Finance Publiques 47: 216-230. 